\title{
They're Natural and Everywhere: How Evaluative Practices Permeate the Organization
}

\author{
Florentine Maier, Institute for Organization and Organizational Behavior, Vienna University of Economics and Business Administration, \\ E-Mail: florentine.maier@wu-wien.ac.at \\ Julia Brandl, Institute for Organization and Organizational Behavior, Vienna University of Economics and Business Administration, \\ E-Mail: julia.brandl@wu-wien.ac.at
}

\begin{abstract}
How do evaluative practices become natural and ubiquitous in an organization? In this paper we integrate findings from previous empirical work on the adoption of evaluative practices in organizations with insights from institutional theory and social psychology research for advancing the understanding of possible states of evaluative practices within organizations and the processes through which organizations become permeated by evaluative practices. Our conceptual model suggests that once evaluative practices have gained a foothold in an organization, they tend to be applied to an increasing number of organizational problems and become taken for granted.
\end{abstract}

Keywords: Evaluative practices, audits, managerial accounting, institutional theory, organizations, diffusion, institutionalization, social psychology

\section{Introduction}

"[...] evaluate again and again, ask again and again, what drives us, idealism, the donor, these are simply the normal questions we ask ourselves [...] check again and again whether I am on the right way, that's fully integrated here."

(Manager of a nonprofit organization)

"[...] we all have to take care that the charity sector does not slide down into business matters. [...] In my opinion this is very important, at the moment I somewhat see the danger that everything becomes business-like, from schools to development aid, that's almost a break with an NPO's organizational culture."

(Manager of another nonprofit organization)

The usefulness of evaluative practices in organizations is far from obvious, not only in nonprofit organizations. The overall trend, however, goes towards an increasing institutionalization and diffu- sion of evaluative practices, in society as well as in organizations in particular. While at the macro level these processes have been covered extensively in previous research (Brandl and Maier 2007; Johnson and Kaplan 1987; Mezias 1990; Mir and Rahaman 2005; Power 1994, 2004; Tiratsoo 2002; Tuckman 1995; Walgenbach 2000; Walgenbach and Beck 2002; Wallerstedt 2002), we know little about how evaluative practices permeate an organization. In this paper we develop a conceptual model of how evaluative practices become "natural and everywhere" in an organization. We conceptualize this as a process of permeation, encompassing institutionalization and diffusion. By institutionalization we mean increasing taken-for-grantedness (Berger and Luckmann 1966; Green 2004); by diffusion we mean the application to an increasing number of organizational problems.

Our analysis contributes to the research on the adoption of evaluative practices by synthesizing findings from previous empirical research (for an overview see Section 3). Previous research has illus- 
trated specific processes which facilitate the permeation of organizations by evaluative practices; however, we lack an explicit understanding of the dynamics contributing to the growing importance of evaluative practices within an organization. By integrating findings from empirical work on the adoption of evaluative practices in organizations and insights from institutional theory and social psychology research we strive to identify possible states of evaluative practices within organizations and to systematize the mechanisms through which organizations become permeated by evaluative practices.

Although our subject is evaluative practice, our arguments are not necessarily limited to this subject area. They may be fruitful for wider institutional research that seeks to understand institutionalization processes at the organizational level (for example Elsbach 2002; Kim, Shin, Oh and Jeong 2007; Zbaracki 1998; Zilber 2002). Contemporary institutional research that looks at the expansion of rationalized practices across organizations provides little understanding of the dynamics within organizations. When it comes to the role of practices within organizations, static concepts predominate, which tend to stress the limited (i.e. symbolic) impact of institutionalized practices on organizational life. Although some institutional scholars question such conceptualizations (for example, Tolbert and Zucker 1996), little attention has been given to outlining an alternative perspective.

After a brief review of the literature on the permeation of organizations by evaluative practices, we introduce our conceptual framework where we distinguish four states that evaluative practices can take on in an organization. We then identify dynamics that promote the permeation of an organization by evaluative practices, distinguishing dynamics between the organization and its environment, and intra-organizational dynamics.

\section{A definition of evaluative practices}

The term "evaluative practice" has so far been used rather scarcely in the literature. As Lindeberg (2007) shows, it can be used as a common denominator for a number of management practices usually considered as separate. Examples for evaluative practices include audits, the "check" in the Deming plan-do-check-act cycle (Deming 1986), management control, managerial accounting, and systematic employee performance evaluations.
Evaluative practices are an essential part of the rational myth (Meyer and Rowan 1977) of management. According to this myth, management is an "all-purpose structure" (Power 2000:113). It reflects central ideas of late modernity: rationality, agency and progress (see Meyer 1994; 2005). The organization itself is responsible for defining its objectives (agency). It develops and implements measures for achieving them (rationality). Evaluative practices then provide performance feedback and ensure that the loop of self-observation and control is neatly closed, enabling potentially infinite improvement (progress) (see Figure 1).

\section{Figure 1: A general schema of the rational management myth}

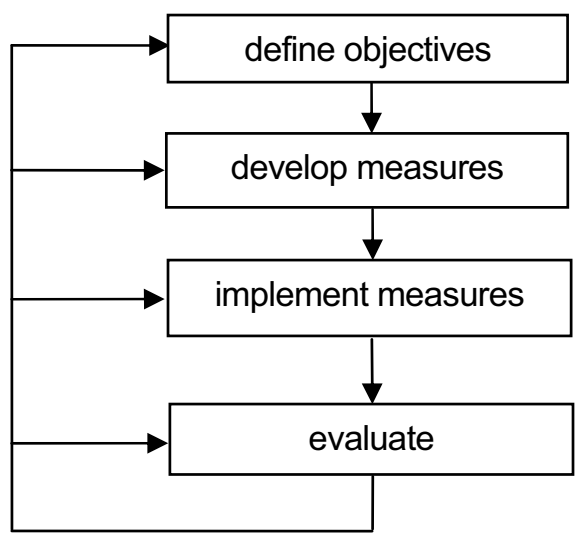

The rational management myth does not contain the possibility of its own failure. The cycle of defining objectives, developing and implementing measures, evaluating, and improving is consummate. Its validity depends on shared beliefs and cannot be disproved empirically (see Scott 1986:199; Walgenbach 1998:276). It is the promise of absolute effectiveness (Deutschmann 1997). Each problem is an opportunity for further improvements.

However, the myth-like character of rational management does not preclude that organizations might live up to the myth occasionally, in which case the myth is descriptive and normative at the same time. From our theoretical background in institutional theory, however, we assume that organizations may not work according to the rational model.

The rational-management myth is an "abstract and generalized concept [...] to be applied to any process" (Townley 2002:550). It can be used to imagine and deal with all kinds of organizations, organizations as a whole (for example total-quality manage- 
ment), and single organizational problems (for example financial management, human resource management). In fact, it can be applied to the self as well, for example through self-enhancement literature (see Bröckling 2004).

Based on this, we define evaluative practices as practices of checking outcomes and processes within an organization that are presented as (1) systematic and (2) aimed towards permanent optimization. The second criterion distinguishes evaluative practices from other calculative practices such as financial accounting and financial auditing, which are presented as systematic, but are aimed towards satisfying the "need for trust in exchange" (Power 2004:772), not necessarily including the aim of permanent optimization of financial matters. It should be emphasized that according to our understanding, evaluative practices do not have to be systematic and optimization oriented in an - howsoever defined - objective way; it suffices that they are presented this way by organizational members. If an evaluative practice is deeply taken for granted, it may be practiced without the constant accompaniment of explanations about its aims. In this case the analyst may have to dig deeper, e.g. by means of searching additional documentary evidence, to unearth the ready-made explanations about aims that an organization associates with the practice. In any case, the decision as to whether a practice is presented as systematic and aimed towards permanent optimization, and thus qualifies as an evaluative practice, will have to rely on the interpretative analysis of accounts of the practice.

Evaluative practices are essential for the maintenance of the rational-management myth in two respects (Meyer 1994): Firstly, they verify the very existence of other elements of rational management by checking and confirming them (for example in documents). Secondly, they enhance the relevance of these other elements by optimizing them and ensuring that organizational members comply with them. Since verification and enhancement take place repeatedly, the rationalized elements are constantly (re-)produced. Because evaluative practices are an integral part of the rational management myth, the ideal of evaluation is immune from the failure of particular evaluation methods. Evaluation tools may go in and out of fashion; however, the idea of the appropriateness of evaluation survives. In the field of auditing, for example, the principle of auditing as a distinctive way of problem solving is still seen as useful and legitimate even though particular auditing methods have failed (for empirical evidence see Fischer 1996; Fogarty 1996; Power 1997).

\section{The permeation of organizations by evaluative practices in previous research}

The emergence and expansion of evaluative practices at the societal level has attracted considerable interest in research. In this section we focus in particular on previous research that addresses the organizational level. At the organizational level, there are two types of research on evaluative practices: One type explores functions of practices; the other looks at the processes through which an organization is permeated by evaluative practices

Research on functions suggests that organizations do not adopt evaluative practices 'passively', but rather that organizations' responses to social pressures lead to different ways in which evaluative practices are applied within an organization. For example, the historical longitudinal case study by Ansari and Euske (1987) examines the use of uniform cost accounting (UCA) in the U.S. Department of Defense. They distinguish three rationales as to why organizations use accounting data (ibid.: 53): for enhancement of efficiency (technical-rational), for pursuing power and influence (socio-political) and for setting up a facade of rationality towards stakeholders (institutional). Their empirical analysis reveals that the actual use of evaluative practices is mostly consistent with the socio-political and institutional perspective.

In a similar vein, Modell (2001) analyzes Norwegian public healthcare organizations to illustrate how organizations respond to institutional pressures to use performance measurement. Their responses range from acquiescent behavior where performance management goes unquestioned, voluntary adoption in the context of anticipated future benefits, through to compliance with coercive pressures resulting from more direct control of the organization by government funding. The study provides a detailed picture of the determinants of the adoption of performance measurement, such as stakeholder homogeneity and the organization's reliance on stakeholders. 
A study on the adoption of audits in Saudi Arabia (Al-Twaijry, Brierley and Gwilliam 2003) finds that internal auditors have limited resources and face many restrictions within the organization. This finding points to a rather limited application of evaluative practices in these organizations.

A complementary stream of research looks at the processes through which an organization is permeated by evaluative practices.

For instance, Mezias and Scarselletta (1994) combine garbage-can and institutional perspectives to develop and test hypotheses about which factors affect the decisions for establishing financialreporting systems by an examination of the decision-making process of a public policy task force. They find that problems in the decision-making process that are associated with disorder make the resolution of financial reporting problems less likely. On the other hand, problems that are associated with order enhance the likelihood for the resolution of financial-reporting problems.

Dent (1991) investigates in a longitudinal case study how accounting emerges as the dominant cultural cognitive code within an organization. His analysis describes how an organization transforms from a social-service culture to a business-oriented culture by focusing on what actors regard as effective communication in their everyday work. The study reveals that organization members slowly develop an understanding of performance reporting and apply it in their communication.

A study of managerial accounts on performance appraisal (Roberts 1998) shows that the development of such an understanding does not occur smoothly, but rather that managers controversially debate the purposefulness of evaluative practices.

Perren and Grant (2000) draw on the process of institutionalization (action, externalization, habitualization) to investigate the development of management accounting routines in four small business organizations. Their study shows that the institutionalization of evaluative practices is also a selfreinforcing process that occurs in accordance with other business developments. Routines that initially seem under the control of the owner become objective facts and common knowledge with the growth of the business.

Mueller and Carter (2005) use an organizational biography perspective to discuss the dynamics of Total Quality Management (TQM) at the organizational level. They argue that any innovation, includ- ing TQM, has a biography with scripts of typical activities and they examine how the dynamics of $\mathrm{TQM}$ can be traced along these scripts. However, in contrast to our perspective, they do not conceptualize TQM as an evaluative practice that permeates the organization, but as a management fashion that fades in the end.

Most recently Dambrin, Lambert and Sponem (2007) present a case study of the processes through which management control systems change in a French pharmaceutical laboratory. Building on a theoretical framework by Hasselbladh and Kallinikos (2000) they distinguish ideals, discourses and control techniques. They argue that the ideal of a new control system "develops into discourses and then techniques" (Dambrin, Lambert and Sponem 2007:174). This process, however, does not necessarily challenge the total organization or "modify the daily activity of organizational actors" (ibid.) because not all of the organizational actors hear emerging discourses, and control techniques may remain incoherent.

Concluding this brief literature review we find that the majority of studies suggest that, over time, organizations tend to adopt evaluative practices. Reflecting a difference in theoretical approaches as well as empirical findings, studies reveal different understandings of what "adoption" means, ranging from decoupled practices to substantial changes in organizational reality. Only research that sees the adoption of evaluative practices as a change in organizational reality assumes that evaluative practices play a constitutive role in organizational life (Hopwood 1987).

Among this work only the case studies by Dent (1991), Perren and Grant (2000) and Dambrin, Lambert and Sponem (2007) explicitly address processes through which evaluative practices become "natural" within the organization. These studies focus on the increasing taken-for-grantedness of evaluative practices. What is not addressed by this research, however, is diffusion within an organization. The studies hardly examine how evaluative practices are applied to an increasing number of organizational problems. However a simultaneous focus on taken-for-grantedness and diffusion is important for understanding the expansion of practices, as Green (2004) emphasizes. Moreover the drivers of permeation are still little systematized.

Our subsequent analysis aims to address these limitations and develop an explicit model of the states of 
evaluative practices within an organization and the dynamics contributing to their growing importance.

\section{States of permeation of organizations by evaluative practices}

We transfer previous research by Green (2004) to the organizational level to develop a framework that helps us to disentangle different states of evaluative practices at the organizational level (see Figure 2). We conceptualize an organization's permeation by evaluative practices along two dimensions: the extent to which evaluative practices are institutionalized within the organization, and their diffusion (i.e., the number of organizational problems to which evaluative practices are applied).

\section{Figure 2: States of permeation of an organization by evaluative practices}

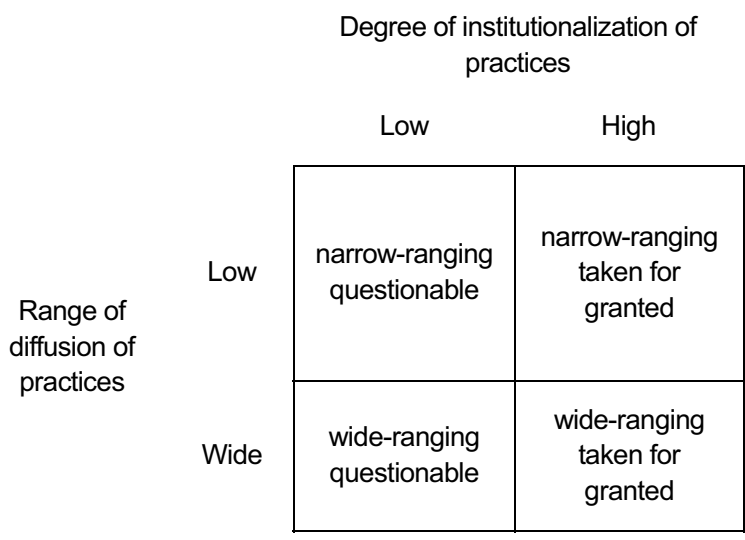

Institutionalization is the degree to which a practice is taken for granted (Green 2004:654). If evaluative practices are only institutionalized to a low degree, they are questionable. In cases of high institutionalization, they are taken for granted.

Taken-for-grantedness means that there is an organizationally shared perception that evaluative practices are reasonable: "This is how these things are done" (Berger and Luckmann 1966 [1969:63]). Organizational members have theories about the reasonability of evaluative practices, but these theories are no longer discussed; they are embraced silently (Tolbert and Zucker 1996:185), but theories can easily be activated on demand to account for practices. The articulation of fundamental concerns about evaluative practices may even irritate or annoy members, since they perceive evaluative practices as "natural" and see no benefits in debating them (as demonstrated by Garfinkel, 1967, in his breaching experiments).

Nevertheless, evaluation talk continues. This talk is relegated to talk in the course of evaluative practices, for example in investigations, working papers, instruction manuals for evaluators, and so on. The production of these texts is a vital component of evaluative practices; it presupposes and by implication perpetuates them. Taken-for-granted evaluative practices are scripted and well rehearsed. Members' roles with regard to evaluative practices are defined and steeped with shared expectations. Categories (for example what is proper documentation, what is an appropriate audit) are settled and infused with shared meaning (Colyvas and Powell 2006: 345).

In contrast, if evaluative practices are questionable, this means that they are fundamentally debated. Organizational members provide detailed explanations as to why evaluative practices should - or should not - be used. This may include official arguments about their basic necessity. This kind of explicit theorizing is a strategy for making sense of the world (Strang and Meyer 1993:493). Explicit theorizing can be highly controversial, as Suddaby and Greenwood (2005) show in their study of the discursive struggle between proponents and opponents of multidisciplinary partnerships in law firms. When a practice becomes more accepted, discursive justification decreases (Green 2004:656; Suchman, 1995:584) and dissident voices fall silent. Hence, as long as organization members are talking or writing about evaluative practices, this indicates that they are not taken for granted (see also Phillips, Lawrence and Hardy 2004: 642).

As evident from the above arguments, our understanding differs from a view of institutionalization drawn from an alternative reading of Meyer and Rowan (1977). We do not view institutionalization as the infusion of an evaluative practice with meaning that is separate and distinct from its technical purpose. We avoid this approach because it tends to create several problems: It presumes the existence of an objective technical rationality, which contradicts the social constructionist foundations of institutional theory (Berger and Luckmann 1966). It implies that there is something like a natural solution for a technical imperative. When it comes to organizations, however, the metaphor of "technicality" is misleading. Organizations are not governed by natural laws of mechanics; they are complex social 
systems. In organizations there are no compulsory or natural developments; alternatives are always possible. Moreover, criteria for defining technically rational solutions are insecure; engineers, economists or entrepreneurs might have very different views on this subject (Walgenbach 2006). When evaluative practices or other elements of the rational management myth are made the subject of analysis, this problem becomes especially virulent: How can we analyze the institutionalization of something that presents itself as the pinnacle of technical rationality? One way out is to choose a point of reference for defining "real" technical rationality. Often this has been done implicitly and with little reflection, taking for granted that official goals espoused by the organization's leaders should be the yardstick, which creates some embarrassing questions about the role of social scientists (Brown 1978). For us also the technically or economically rational is symbolic; that is to say, infested with meaning (Zucker 1977). In organizations there is no purely economic or technical sphere that is somehow exempt from the symbolic (Friedland and Alford 1991; Munro 1995; Powell 1991).

Based on these considerations, we operationalize taken-for-grantedness at the organizational level as the continuous exercise of an evaluative practice, which may involve talk in the course of it, in the absence of talk about the practice (in analogy to Green's definition of taken-for-grantedness at the organizational field level, cf. Green 2004:665). Taken-for-grantedness at the level of the organization can occur even if the majority of its members grumble about evaluations in private. In fact, due to their limited involvement individuals are extremely unlikely to become so deeply socialized by an organization that they come to take all of its practices for granted (Czarniawska-Joerges 1992:120). For an analysis at the organizational level, only what they do in their role as a member of the organization matters. To know to what extent evaluative practices are taken for granted for an organization, one has to analyze the communications and artifacts that are produced and used in the course of its normal activities (for example meetings, documents, public speeches by representatives). It would not be appropriate to ask all members for their opinion on evaluative practices and piece a picture together from that, as many of the views voiced in such interviews might never influence the workings of the organization. This is not to say that views of individual organization members are not important and interesting. However, such an analysis would not be located at the level of the organization, but rather of the individuals.

The second dimension along which we conceptualize an organization's permeation by evaluative practices is diffusion. Our concept of diffusion is an attempt to translate the adoption of practices by different organizations within an organizational field (Green 2004:656) to the organizational level. Green conceptualizes the adoption of a practice as manifestation in patterns of action. In his model, diffusion is operationalized as the proportion of a population that has adopted the practice in question (ibid.). In analogy to this, we look at patterns of action within organizations. Wide-ranging then means that evaluative practices are applied as solutions to many organizational problems, whereas narrowranging means that evaluative practices are restricted to a few problems. Problems and solutions are understood in the sense of Cohen, March and Olsen (1972). That is to say, problems do not exist according to some objective criterion, but only become real for the organization the moment they are identified by members. Neither is the connection between particular problems and solutions a natural one. Solutions make suggestions for which questions can be addressed. Organizational members continuously prepare solutions without necessarily having identified a problem as a priory. If a problem occurs, these solutions can be applied. A practice may therefore become more wide-ranging by extending its application to existing problems, or by creating new problems to which it can be applied. In case of wide-ranging evaluative practices, organizational members see evaluative practices as universally applicable: whenever they need to accomplish a task in their roles as organizational members, they refer to evaluative practices as a solution. For example, in an organization that commits itself to an integrated audit such as the one proposed by the European Foundation for Quality Management (EFQM), or runs a number of separate audits, say, a quality audit, a work and family audit, and an environmental audit, evaluative practices would be considered as wide-ranging. Diffusion may not necessarily involve the inclusion of new user groups (Ansari and Euske 1987) or the devotion of increasing amounts of time, as evaluative practices may be automated and to a large extent fulfilled by information systems. 
In contrast, evaluative practices are narrow-ranging when they are relevant for solving only a very limited number of problems in organizations. For example, in an organization where financial statements are evaluated and nothing else, evaluative practices would be considered as narrow-ranging.

Together the dimensions of institutionalization and diffusion constitute the dimensions along which an organization's permeation by evaluative practices can be discussed. Evaluative practices in an organization can, therefore, take on four different states: from narrow-ranging and questionable to wideranging and taken-for-granted (see Figure 2). Evaluative practices can take on any of these states in an organization, but - in the context of cultural rationalization - they tend to develop from a narrow-ranging and questionable state into a wideranging and taken-for-granted state.

In organizations where evaluative practices have a narrow-ranging questionable state, they are applied to few organizational problems and remain highly contested. This state is most unstable. If evaluative practices do not institutionalize, which is difficult if their diffusion within the organization is low, evaluative practices are unlikely to last.

By using an Austrian secondary school as an example we illustrate a narrow-ranging and questionable evaluative practice: When the Austrian Ministry of Education initiated a program to promote science teaching in secondary schools, a number of teachers at that school decided to participate. They wrote project proposals and received considerable grants. In exchange for these funds, however, they had to participate in an evaluation scheme to assess the teaching outcomes of these projects that went beyond anything they had expected. The program evaluation was the only form of evaluative practices within the school. In addition, the school ran a rudimentary financial audit, which aimed towards building trust in exchange and not towards optimization of financial matters. Teachers saw the monitoring of teaching outcomes as unnecessary red tape and an assault on their professional expertise. They refused to conduct the evaluations properly, communicated their indignation to the program agency (for example: at a program workshop where they should have been taught the principles of evaluation, in e-mails to the program managers, and in critical sections in the evaluation reports). In the end, with the support of the headmaster, teachers at this school stopped applying for further funding through this program.

Evaluative practices are narrow-ranging and taken for granted in organizations where they are applied to few organizational problems, but are highly institutionalized there. In this case rational management is a professional standard. Within the organization there is no controversy that evaluative practices are an appropriate solution for the specific task at hand, but they are considered as irrelevant for other tasks. For example, a small family business may as a matter of course subject is costs and sales figures to periodic evaluation by means of management accounting, but may not even think about extending this approach to other problem areas (for example, product quality or employee and customer satisfaction).

Wide-ranging questionable evaluative practices characterize an organization if they are applied to an ample number of organizational problems but are highly contested. For the organization this is a very exhausting state, since it is engaged in extensive re-negotiation of appropriate solutions.

Examples for this state of evaluative practices can be found in today's Austrian universities. Here within the past ten years or so, a strong movement has taken place away from the traditional bureaucracy and democratic ideals in the spirit of the 1970s, towards new public management ideals of economic efficiency and control (see also Townley 1997). At the authors' university, for example, ten years ago the first attempts at the evaluation of teaching quality were introduced. Today almost everything from strategy to international outreach and research is subject to comprehensive evaluations. However, this expansion of evaluative practices has been accompanied by dissenting voices, complaints about increased workloads, an emphasis on quantity at the expense of quality, research at the expense of teaching, pure science at the expense of applied science, loss of democratic participation rights and job security, and so on. The rector's council is currently working on an audit of employee satisfaction.

Evaluative practices are wide-ranging and taken for granted in an organization when they are uncontested and applied to many organizational problems. This is the case in an organization that wholeheartedly and without doubt emulates the ideal of modern management. An example of such an organization would be one that has fully adopted the concept of TQM: 
"In contrast to older concepts of quality assurance that are limited to control strategies for the production process and only cover technical and functional product quality, TQM extends quality control to all organizational activities and also includes, besides products and the production process, all communication with customers." (Bröckling 2004:136, translated by the authors)

Customer satisfaction is monitored, for example, through surveys. Because customer satisfaction is dependent on employee service quality, employee performance is also continuously monitored. Employee performance in turn is seen as dependent on supervisors' leadership performance. Consequently, supervisors are also evaluated. In the extreme case this results in 360-degree performance feedback for all members of the organization. On top of this, TQM also prescribes the continuous improvement of the quality management system itself, an evaluation of the evaluative practice (ibid.).

\section{Processes of an organization's permeation by evaluative practices}

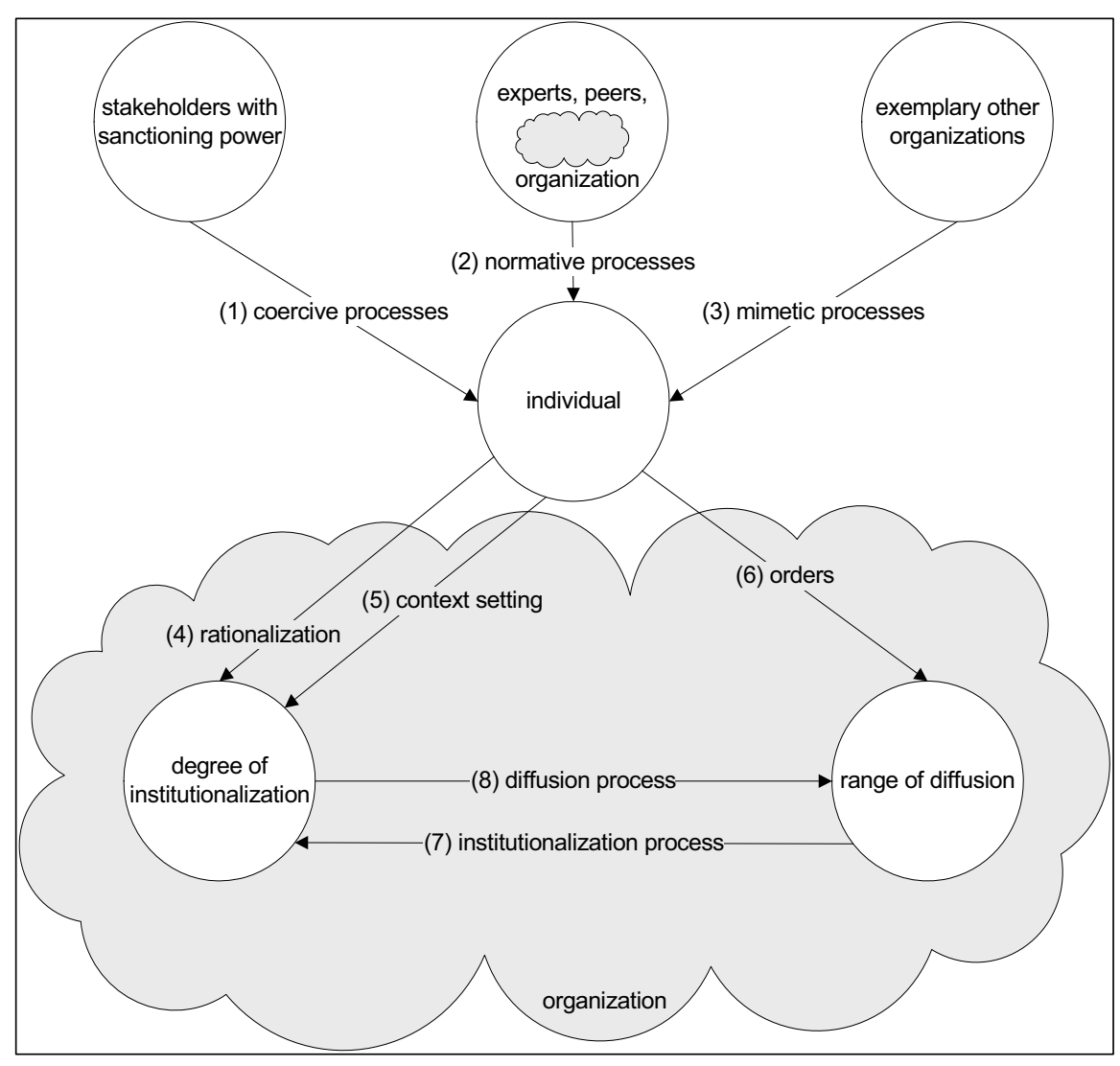

Above we have outlined four states of permeation of an organization by evaluative practices. In this section we explain how evaluative practices in an organization develop from narrow- to wide-ranging, and from questionable to taken-for-granted - in other words, how evaluative practices permeate an organization. Institutional theory and rhetorical theory of diffusion (Green 2004) provide explanations at the societal level, but remain vague about processes at the organizational level. To shed some light on the issue at this level we draw on socialpsychology research. This perspective helps us to understand dynamics of permeation at the individual level.
We distinguish between two forms of dynamics that promote the permeation of an organization by evaluative practices: dynamics between the organization and its environment (see arrows 1 to 6 in Figure 3), and intra-organizational dynamics (arrows 7 and 8). In the following sections these dynamics are laid out in detail.

\section{Figure 3: Processes of an organization's permeation by evaluative practices}

2) normative processes

(3) mimetic processes

5.1 Dynamics between the organization and its environment

We conceptualize the environment of an organization as "enacted" by members (Weick 1979). No environmental factor can enter the organization directly. Instead, environmental influences need to be noticed by an individual, communicated by this individual as part of her member role, and the communication needs to be recognized by other members. For example, a new customer demand for ISO (International Organization for Standardization) certification can only influence the organization if an organizational member notices it, communicates it within the organization, and other members react to the communication. If only customers or external 
ISO certifiers saw the need for certification, this would not be sufficient.

This conceptualization of the connection between the organization and its environment implies two relationships: the environment influences individuals, and in their role as organizational members individuals influence the organization. To examine how evaluative practices enter the organization we will focus on these relationships in turn.

As the first step, evaluative practices need come to the attention of individuals and attract their interest. This step is regardless of the question of whether they will ever act upon their new knowledge in their role as organizational members. It can take place through coercive, mimetic and normative processes (DiMaggio and Powell 1983).

Coercive processes take place if individuals notice constraints or requirements that call for evaluative practices which emanate from stakeholders that have power over the organization (see arrow number 1 in Figure 3). Examples could be the abovementioned customers who insist on ISO certification (for example towards key suppliers in the automotive industry), new laws, demands of donors (like in our introductory quote by a nonprofit manager), or major shareholders. Since ideas of self-controlled instrumental action and progress are essential components of modern "world policy" (Meyer 2005), evaluative practices are gaining legitimacy in more and more aspects of social life. In the case of evaluative practices the demands of the environment are usually homogenous, as evaluative practices enjoy legitimacy among all stakeholders. Acquiescence to coercive pressures is therefore most likely (cf. Oliver 1991: 152).

Individuals can also seek guidance on correct organizational practices from experts or the company of peers. In this case normative processes take place; for example, through formal education, professional networks, and organizational socialization (see arrow number 2 in Figure 3). Here we find another driver that contributes to the permeation of organizations by evaluative practices: the growing prevalence and importance of business education (cf. Moon and Min Wotipka 2006). Individuals, who have undergone business education whether academic or other, are more likely than others to introduce evaluative practices (Hwang and Powell 2007). In addition, individuals who have been socialized in organizations or professional networks where evaluative practices are taken for granted tend to introduce these practices to their new workplace if they take up a job at a different organization (for empirical evidence on the introduction of managerial practices by new members coming from managerialized organizations, see for example ibid. and Dent 1991).

Sometimes individuals are not quite sure what important stakeholders expect from the organization. In this case of uncertainty mimetic processes take place. Members of less successful or new organizations look at successful or well-established organizations for guidance. In the case of evaluative practices this leads to an accelerative dynamic: organizations often proudly demonstrate their evaluative practices and present themselves as more rational and progress-oriented than they actually are. Often the façade of evaluative practices looks much more appealing than their intra-organizational workings (which may involve conflicts, proliferating paperwork, fiddling with figures, excessive fixation on metrics, or metrics gathering proverbial dust in drawers, see for example Ansari and Euske 1987, Maier 2008, Wruck and Jensen 1994, Zbaracki 1998, and for a particularly gruesome case, Chwastiak 2006). This causes individuals to systematically over-estimate the evaluative practices of other exemplary organizations. It is also an important mechanism that promotes evaluative practices within the whole organizational field: since the organization itself, after it has started to engage in some kind of evaluative practice, is highly likely to trumpet it just as loudly, it will in turn create a positively biased impression for others.

Since we conceptualize the organizational environment as enacted, coercive, mimetic and normative processes are not unambiguously dictated by the environment. As Weick (1979) puts it: "believing is seeing". Individuals with a managerial background will be more sensitive towards coercive pressures towards evaluation in the organization's environment, and they will be more likely to orientate themselves by organizations that display rational management. Organizations incorporating high levels of rational management will be more likely to hire such members, and will be more likely to listen to their ideas. This means that the organization has some leeway in deciding how much it wants to be pushed towards evaluative practices by its environment. It can hire different people, craft its dependencies differently, and look towards different role models for orientation. It should be noted, though, 
that "the environment is enacted" does not mean that the environment can be imagined arbitrarily. Socially constructed reality is nevertheless "hard" reality, involving serious dangers such as bankruptcies.

As the second step for evaluative practices to enter the organization, the individual who has been impressed by evaluative practices needs to somehow transfer them into the organization and achieve diffusion and/or institutionalization. He can do this in three ways: rationalization, context setting, and orders. These three ways can be combined, and in most organizations they probably are.

Firstly rationalization promotes institutionalization (see arrow number 4 in Figure 3). It involves theorizing (Suddaby and Greenwood 2005) and rhetoric (Green 2004) to convince individuals that evaluative practices make sense in their role as organizational members. Put simply, this might, for example, involve a business manager approaching senior executives and persuading them that formal evaluation is needed. A senior executive may then think: "Our minds were opened" (Dent 1991:717). In our model we depict the first perspective on this event (the business manager persuades the senior executive) as rationalization. The second perspective (the senior executive is persuaded by the business manager) is depicted as normative process.

A member has higher chances of being successful with rationalizing if he is perceived as having a legitimate right to speak; for example, if he is a manager or considered an expert on the subject. Another factor that can help or hinder rationalization is the existing organizational expectation structure. If it incorporates values of rationality, transparency and progress, it is well "connectable" (Luhmann 2000:56) to evaluative practices. Members will find it relatively easy to communicate the idea successfully within the organization. However, a skilled speaker may be able to redefine previous organizational reality and create connections ex post. An example for this are the young business managers in Dent's (1991) case study of the introduction of new accounting practices in a railroad company, which managed to build on the company's cherished value of modernity (understood as modern railroad techniques) to argue for the necessity of introducing modern accounting techniques. Change was promoted by arguing that it is actually not a major change (cf. Suddaby and Greenwood 2005:53).
Secondly an individual can promote institutionalization through context setting. Such strategies might include silencing powerful dissidents by keeping them busy with other tasks, disempowering them (for example by changing participation rights), or - a very crude strategy - telling them to stop questioning evaluative practices, penalizing them for criticism, up to excluding dissidents from the organization (Green 2004:659).

Thirdly an individual who wants to promote evaluative practices can aim primarily at diffusion. That is to say, she may forego the institutionalization of the idea, may not bother about whether there is a lot of discussion about the practice, and just focus on diffusion (at least at the beginning). Diffusion can be achieved directly by giving orders provided that the order meets certain criteria. Who can give what kind of orders to whom within an organization is subject to limitations. Obviously the higher the hierarchical position, the greater the possibilities. But employees are protected by laws and contracts, and sometimes they don't obey orders that lie within the limits of formal authority (for example, if they make a mistake).

\subsection{Intra-organizational dynamics}

Above we have discussed dynamics between the organization and its environment. In this section we focus on intra-organizational dynamics that promote permeation by evaluative practices. We identify two processes: institutionalization and diffusion. As we have pointed out above, evaluative practices can be introduced to an organization directly through orders. If orders are not accompanied by rationalization, this implies that evaluative practices will be diffused within the organization, i.e., applied to problems, but not institutionalized, i.e. taken for granted. However a number of mechanisms make it very likely that practices that are engaged in for some time become taken-for-granted, i.e., that diffusion (as a state) increases institutionalization (as a state). We call this development from diffusion to institutionalization an institutionalization process, indicated in Figure 3 by arrow number 7 . We distinguish between two basic mechanisms through which this process operates: habitualization and personnel turnover.

Habitualization works at the individual level. If members repeatedly conduct evaluations, or are repeatedly subjected to them, they tend to get used to them because it saves them cognitive effort (Ber- 
ger and Luckmann 1966:56-58). After several repetitions other members tend to develop shared reciprocal typifications of these practices ("there we go, he's evaluating again") or types of actors ("here comes the evaluator again") (Perren and Grant 2000; Tolbert and Zucker 1996). Research in social psychology has identified escalating commitment as another important underlying mechanism of habitualization. Commitment to a course of action is likely to become binding if those actions are publicly visible, irreversible, and involve high choice. The underlying social psychological mechanism is avoidance of cognitive dissonance: "I have participated in something. I am a reasonable person. Therefore the thing I have participated in must have been reasonable" (see Aronson 1994:185-250 for a detailed summary of research on the workings of cognitive dissonance). A large amount of research on escalating commitment supports this mechanism and explores further conditions (see for example Staw 1996). Commitment also develops if members make concessions to some small form of evaluation, for example "only symbolic" evaluations for image purposes, which are then extended. As Janis and King (1958) have shown in their experimental study on the influence of role playing on opinion change, participants who argue publicly in favor of a position that differed from their personal opinion are likely to actually take on this new position.

The second form of institutionalization process is turnover of personnel. This form of institutionalization process takes place at the population level. When new members enter the organization they encounter the evaluative practices there as fact-like, resulting in deeper taken-for-grantedness of the practice at the organizational level (Perren and Grant 2000:397). Personnel turnover takes place naturally, but it can also be consciously managed by powerful groups to develop the organization in a particular direction. For example managers may deliberately try to get rid of people who are critical of and recruit people who are neutrally or favorably disposed towards evaluative practices.

So far we have outlined how diffusion leads to institutionalization. But institutionalization (as a state) also increases diffusion (as a state). We call this process diffusion process, indicated in Figure 3 by arrow number 8 .

Here the basic mechanism is that organizational members who take evaluative practices for granted use evaluation as a solution for new problems they encounter, or even look for problems to which they can apply their newfound solution (Cohen et al., 1972). In the case of evaluative practices, application to new problems is particularly likely because evaluative practices claim universal applicability. Since the rational management myth is a generalized concept (see Section 2), evaluative practices can be applied to virtually any kind of organizational problem. Of course unlimited diffusion of evaluative practices would at some point lead to severe problems within the organization (for example excessive reporting, Strausz 2006). Human imagination, however, is unlimited. Members who take evaluative practices for granted will tend to come up with new ideas for how they could be put to use. As Power (1996) has pointed out, claims about the inability of evaluative practices to capture intricacies that require professional expertise can be refuted by "making things auditable". Any social activity that can be understood as an instrumental action with potential for continuous improvement can be subjected to formal evaluation.

Besides these cognitive reasons, organizational members might also have personal stakes in evaluations: "hungry people with a mission" (Dent 1991:716). This is particularly the case with members for whom evaluative practices are part of their job.

"People who conduct evaluations have a direct career and income interest. Therefore they strive to extend evaluations to ever-increasing areas, to intensify them, and to conduct them in shorter and shorter intervals." (Frey 2007:213, translation by the authors)

The basic mechanism through which diffusion processes take place is the movement of organizational members with an affinity to evaluative practices (whether for cognitive or interest-driven reasons) to different problem areas. This might take place in the form of promotions, job rotation, and participation in projects.

\section{Discussion}

In this paper we aimed at addressing how evaluative practices permeate an organization. We addressed two questions: What are the states that evaluative practices can take on within the organization? What are the processes through which permeation occurs? To examine these questions we used research from institutional theory and social psychology. 
Our conceptual framework of states of permeation provides a tool for diagnosing to what degree an organization is permeated by evaluative practices. The framework makes suggestions for operationalizing two important dimensions of permeation at the organizational level: diffusion and institutionalization. Our model of permeation by evaluative practices systematizes processes that promote that evaluative practices become natural and ubiquitous in an organization. The model suggests that permeation is characterized by several circular causalities. Once evaluative practices have gained a foothold in an organization, they tend to diffuse to more and more organizational problems and become institutionalized.

The conceptualization of diffusion and institutionalization as intra-organizational phenomena is an extension to institutional theorizing, which for the past three decades has mainly focused on the societal level, examining the movement of ideas and practices across organizations. In doing so, our work reconnects the so-called "old" institutionalism that studied processes within organizations (see for example Selznick 1949) with more recent institutional theorizing that refers to the inter-organizational level. We suggest that this integration is useful for a more systematic analysis of the dynamics of practices within organizations. The proposed framework may thus stimulate further research on institutionalization (and diffusion) inside the organization.

More and more organizations operate in environments characterized by "world policy" (Meyer 2005), where self-controlled instrumental action and progress are valued and evaluative practices are therefore perceived positively. Considering the expansion of modern management knowledge (Lernik and Lunman 2004; Sahlin-Andersson and Engwall 2002), we anticipate that organizations where evaluative practices are questionable and narrowranging will become more rare. The school discussed previously was able to resist evaluative practices because it was not dependent on the science program for financial or symbolic resources. Powerful parties within the organization such as the headmaster and the teachers believed in professional expertise and discretion instead of rational management. The managers of the science program were the only stakeholders who demanded evaluative practices, and the program was not crucial for the school's operation. Increasingly, however, organizations are faced with changes in their envi- ronment that increase the demand for evaluative practices.

Our model of the processes through which permeation occurs systematizes previous research on the adoption of evaluative practices in organizations in the form of qualitative case studies by discussing it with insights from institutional theory and social psychology research. It calls for further research to provide more knowledge about the particular sequence of states (or stages, in that case) and the importance of mechanisms through which an organization is permeated by evaluative practices.

The circular causalities outlined in our model of processes (Fig. 3) suggest that once evaluative practices have gained a foothold in an organization, they develop from narrow-ranging to wide-ranging and from questionable to taken or granted. However, our model does not necessarily imply a particular sequence of states that applies to all kinds of organizations, e.g. that evaluative practices generally enter an organization as narrow-ranging and questionable and then develop into wide-ranging and taken for granted via a particular path of intermediate (narrow-ranging/taken-for-granted, wide-ranging/ questionable) stages.

We suspect that evaluative practices can enter an organization via the narrow-ranging and questionable state (like in the school that had to evaluate its special science projects), via the narrow-ranging and taken-for-granted state (think of a firm that subjects its sales figures to analysis by methods of management accounting), and via the wide-ranging questionable state (for example, if after a takeover a parent company remodels all management processes in a subsidiary). Some organizations may also be "born" fully permeated by evaluative practices (for example, a business organization founded by and staffed with people with a professional background in business management). Further research needs to examine whether this is indeed the case, or if evaluative practices always start as narrowranging and questionable. If any state could be the starting level, further research should explore what determines the particular level.

Our model outlines the processes that contribute to permeation. It suggests that taken-for-grantedness and diffusion increase, but it does not necessarily imply any order of states of permeation, in particular not with regard to the mixed narrowranging/taken-for-granted and wide-ranging/questionable) states. More research, especially of the 
empirical kind, is needed to clarify this issue. Such research should examine which processes typically start permeation, and in which sequences those processes unfold. To reconstruct the processes that have led to changes in permeation, we suggest using the processes identified in our model as sensitizing concepts. They provide categories that need to be examined for their relevance and characteristics in the particular case.

Such research would have to cover diffusion and institutionalization. To operationalize institutionalization, interpretative methods are needed, since talk about evaluative practices needs to be distinguished from talk in the course of evaluative practices. For this purpose, a corpus of suitable data needs to be identified first. These need to be data produced by the organization, such as written and oral communication; also artifacts (such as management information systems) could be informative (see for example van Leeuwen, 2005). After the corpus has been delineated, the data are then categorized as talk about or as talk in the course of evaluative practices. If this method is applied to cross-sectional data, the state of permeation can be assessed. If it is applied to different points in time, changes in permeation become visible.

This paper also provides some basic ideas on how high and low levels of diffusion in an organization can be distinguished. Diffusion can be operationalized by reconstructing which problems the organization deals with, and to how many of these problems evaluative practices are applied. This kind of information can be obtained from documents, interviews, or participant observation. In line with our understanding that the number of organizational problems varies across organizations and may change over time, we suggest using relative and not absolute measures for examining the degree of diffusion (e.g., 70 percent of all organizational problems). To decide what proportion of problems actually deserves the attribute "high" or "low" remains a task for further research.

Another question for further research is to what extent our analysis can be generalized. We developed our analysis for the subject of evaluative practices and think that some of the characteristics of evaluative practices lead to peculiarities in their diffusion (for example their power effects of surveillance and control tend to make them especially popular with managers). However, there are no indications that the main processes outlined in the model may not be applicable to other practices that are institutionalized at a societal level (for example, equal-opportunity programs or employee training and development). Further research should examine using qualitative methods whether this is indeed the case. By adding adjustments and extensions, a general model of permeation at the organizational level could thereby be developed.

\section{Acknowledgements}

We are grateful to two anonymous reviewers, John W. Meyer, Michael Meyer and Anahid Aghamanoukjan for their valuable comments. Earlier versions of this paper were presented at the $3^{\text {rd }}$ Workshop on Institutional Theory in Bergamo (23-24 March 2007) and at the $2^{\text {nd }}$ Conference on Rhetoric and Narratives in Management Research in Barcelona (31 May-2 June 2007).

\section{References}

Al-Twaijry, Abdulrahman A.M., John A. Brierley, and David R. Gwilliam (2003): The Development of Internal Audit in Saudi Arabia: An Institutional Theory Perspective, Critical Perspectives on Accounting, 14 (5): 507-531.

Ansari, Shahid L. and Kenneth J. Euske (1987): Rational, Rationalizing, and Reifying Uses of Accounting Data in Organizations, Accounting, Organizations and Society, 12 (6): 549-570.

Aronson, Elliot (1994): Sozialpsychologie: Menschliches Verhalten und gesellschaftlicher Einfluss, Spektrum Akademischer Verlag: Heidelberg.

Austin, John L. (1975): How To Do Things with Words: The William James Lectures Delivered at Harvard University in 1955, 2nd ed., Harvard University Press: Cambridge, Mass.

Berger, Peter L. and Thomas Luckmann (1966): The Social Construction of Reality: A Treatise in the Sociology of Knowledge, Doubleday: New York.

Berger, Peter L. and Thomas Luckmann (1969): Die gesellschaftliche Konstruktion der Wirklichkeit: Eine Theorie der Wissenssoziologie, Fischer: Frankfurt am Main.

Brandl, Julia and Florentine Maier (2007): Development of Audit Objectives in the People's Republic of China, in: Diana Sharpe and Harukiyo Hasegawa (eds.): New Horizons in Asian Management: Emerging Issues and Critical Perspectives, Palgrave MacMillan, New York, 183-200.

Bröckling, Ulrich (2004): Totale Mobilmachung: Menschenführung im Qualitäts- und Selbstmanagement, in: Ulrich Bröckling, Susanne Krasmann, and Thomas Lemke (eds.): Gouvernementalität der Gegenwart: Studien zur Ökonomisierung des Sozialen, Suhrkamp, Frankfurt am Main, 131-167.

Brown, Richard Harvey (1978): Bureaucracy as Praxis: Toward a Political Phenomenology of Formal Organizations, Administrative Science Quarterly, 23 (3): 365-382.

Chwastiak, Michele (2006): Rationality, Performance Measures and Representations of Reality: Planning, Programming and Budgeting and the Vietnam War, Critical Perspectives on Accounting, 17 (1): 29-55. 
Cohen, Michael D., James G. March and Olsen, Johan P. (1972): A Garbage Can Model of Organizational Choice, Administrative Science Quarterly, 17 (1): 1-25.

Colyvas, Jeannette and Walter W. Powell (2006): Roads to Institutionalization: The Remaking of Boundaries Between Public and Private Science, Research in Organizational Behavior, 27: 305-353.

Czarniawska-Joerges, Barbara (1992): Exploring Complex Organizations: A Cultural Perspective, Sage: Newbury Park, CA.

Dambrin, Claire, Caroline Lambert and Samuel Sponem (2007): Control and Change - Analysing the Process of Institutionalization, Management Accounting Research, 18 (2): 172208.

Deming, W. Edwards (1986): Out of Crisis Cambridge, MA: Massachusetts Institute of Technology, Center for Advanced Engineering Study.

Dent, Jeremy F. (1991): Accounting and Organizational Cultures: A Field Study of the Emergence of a New Organizational Reality, Accounting, Organizations and Society, 16 (8): 705732.

Deutschmann, Christoph (1997): Die Mythenspirale. Eine wissenssoziologische Interpretation industrieller Rationalisierung. Soziale Welt, 48 (1): 55-70.

DiMaggio, Paul J. and Walter W. Powell (1983): The Iron Cage Revisited: Institutional Isomorphism and Collective Rationality in Organizational Fields, American Sociological Review, 48 (2): 147-160.

Elsbach, Kimberly D. (2002): Intraorganizational Institutions, in: Joel A. C. Baum (ed.): The Blackwell Companion to Organizations, Blackwell, Oxford, 37-57.

Fischer, Michael J. (1996): "Realizing" the Benefits of New Technologies as a Source of Audit Evidence: An Interpretative Field Study, Accounting, Organizations and Society, 21 (2/3): 219-242.

Fogarty, Timothy J. (1996): The Imagery and Reality of Peer Review in the US: Insights from Institutional Theory, Accounting, Organizations and Society, 21 (2/3): 243-267.

Frey, Bruno S. (2007): Evaluierungen, Evaluierungen... Evaluitis, Perspektiven der Wirtschaftspolitik, 8 (3): 207-220.

Friedland, Roger and Robert R. Alford (1991): Bringing Society Back In: Symbols, Practices, and Institutional Contradictions, in: Paul J. DiMaggio and Walter W. Powell (eds.): The New Institutionalism in Organizational Analysis, University of Chicago Press, Chicago, 232-263.

Garfinkel, Harold (1967): Studies in Ethnomethodology, Prentice Hall: Englewood Cliffs, NJ.

Green, Sandy Edward Jr. (2004): A Rhetorical Theory of Diffusion, Academy of Management Review, 29 (4): 653-669.

Hasselbladh, Hans and Jannis Kallinikos (2000): The Project of Rationalization: A Critique and Reappraisal of NeoInstitutionalism in Organization Studies, Organization Studies 21, (4): 697-720.

Hopwood, Anthony G. (1987): The Archaeology of Accounting Systems, Accounting, Organizations and Society, 12 (3): 207234.

Hwang, Hokyu and Walter W. Powell (2007): The Rationalization of Charity: The Manifestations of Professionalization in the Nonprofit Sector, Paper presented at the 23rd EGOS Colloquium, Vienna, Austria.
Janis, Irving L. and Bert T King (1958): The Influence of Role Playing on Opinion Change, in: Eleanor E. Maccoby, Theodore M. Newcomb and Eugene L. Hartley (eds.): Readings in Social Psychology, 3rd ed., Holt, Rinehart and Winston, New York, 472-482.

Johnson, H. Thomas and Robert S. Kaplan (1987): Relevance Lost: the Rise and Fall of Management Accounting, Harvard Business School Press: Boston, MA

Kim, Tai-Young, Dongyoub Shin, Hongseok Oh and YoungChul Jeong (2007): Inside the Iron Cage: Organizational Political Dynamics and Institutional Changes in Presidential Selection Systems in Korean Universities, 1985-2002, Administrative Science Quarterly, 52 (2): 286-323.

Lernik, Jon Erland and Randi Lunnan (2004): Contrasting Perspectives on the Diffusion of Management Knowledge, Management Learning, 35 (3): 287-302.

Lindeberg, Tobias (2007): The Ambiguous Identity of Auditing, Financial Accountability \& Management, 23 (3): 337-349.

Luhmann, Niklas (2000): Organisation und Entscheidung, Westdeutscher Verlag: Opladen et al.

Maier, Florentine (2008): The Social Construction of Old Age in Unemployment, doctoral thesis, Vienna University of Economics and Business Administration.

Meyer, John W. (1994): Social Environments and Organizational Accounting, in: Richard W. Scott and John W. Meyer (eds.): Institutional Environments and Organizations, Sage, Thousand Oaks, 121-136.

Meyer, John W. (2005): Weltkultur: Wie die westlichen Prinzipien die Welt durchdringen, Georg Krücken (ed.), Suhrkamp: Frankfurt am Main.

Meyer, John W. and Brian Rowan (1977): Institutionalized Organizations: Formal Structure as Myth and Ceremony, American Journal of Sociology, 83 (2): 340-363.

Mezias, Stephen J. (1990): An Institutional Model of Organizational Practice: Financial Reporting at the Fortune 200, Administrative Science Quarterly, 35 (3): 431-457.

Mezias, Stephen J. and Mario Scarselletta (1994): Resolving Financial Reporting Problems: An Institutional Analysis of the Process, Administrative Science Quarterly, 39 (4): 654-678.

Mir, Monir Zaman and Abu Shiraz Rahaman (2005): The adoption of International Accounting Standards in Bangladesh: An Exploration of Rationale and Process, Accounting, Auditing \& Accountability Journal, 18 (6): 816-841.

Modell, Sven (2001): Performance Measurement and Institutional Processes: A Study of Managerial Responses to Public Sector Reform, Management Accounting Research, 12 (4): 437-464.

Moon, Hyeyoung and Christine Min Wotipka (2006): The Worldwide Diffusion of Business Education, 1881-1999: Historical Trajectory and Mechanisms of Expansion, in: Gili S. Drori, John W. Meyer and Hokyu Hwang (eds.): Globalization and Organization, Oxford University Press, Oxford, 121-136.

Mueller, Frank and Chris Carter (2005): The Scripting of Total Quality Management within its Organizational Biography, Organization Studies, 26 (2): 221-247.

Munro, Rolland (1995): Managing by Ambiguity: Archaeology of the Social in the Absence of Management Accounting, Critical Perspectives on Accounting, 6 (5): 433-482.

Oliver, Christine (1991): Strategic Responses to Institutional Processes, Academy of Management Review, 16 (1): 145-179. 
Perren, Lew and Paul Grant (2000): The Evolution of Management Accounting Routines in Small Businesses: A Social Construction Perspective, Management Accounting Research, 11 (4): 391-411.

Phillips, Nelson, Thomas B. Lawrence, and Cynthia Hardy (2004): Discourse and Institutions, Academy of Management Review, 29 (4): 635-652.

Powell, Walter W. (1991): Expanding the Scope of Institutional Analysis, in: Paul J. DiMaggio and Walter W. Powell (eds.): The New Institutionalism in Organizational Analysis, University of Chicago Press, Chicago, 183-203.

Power, Michael (1994): The Audit Explosion, Demos: London.

Power, Michael (1996): Making Things Auditable, Accounting, Organizations and Society, 21 (2-3): 289-315.

Power, Michael (1997): The Audit Society: Rituals of Verification, Oxford University Press: Oxford.

Power, Michael (2000): The Audit Society: Second Thoughts, International Journal of Auditing, 4 (1): 111-119.

Power, Michael (2004): Counting, Control and Calculation: Reflections on Measuring and Management, Human Relations, 57 (6): $765-783$.

Roberts, Gary E. (1998): Perspectives on Enduring and Emerging Issues in Performance Appraisal, Public Personnel Management, 27 (3): 301-319.

Sahlin-Andersson, Kerstin and Lars Engwall (2002): The Expansion of Management Knowledge: Carriers, Flows, and Sources, Stanford University Press: Stanford.

Scott, W. Richard (1986): Grundlagen der Organisationstheorie, Campus Verlag: Frankfurt et al.

Selznick, Philip (1949): TVA and the Grass Roots, University of California Press: Berkeley, CA.

Strang, David and John W. Meyer (1993): Institutional Conditions for Diffusion, Theory and Society, 22(4): 487-511.

Strausz, Roland (2006): Buried in Paperwork: Excessive Reporting in Organizations, Journal of Economic Behavior \& Organization, 60 (4): 460-470.

Staw, Barry M. (1996): Escalation Research: an Update and Appraisal, in: Zur Shapira (ed.): Organizational Decision Making, Cambridge University Press, Cambridge, 191-215.

Suchman, Mark C. (1995): Managing Legitimacy: Strategic and Institutional Approaches, Academy of Management Review, 20 (3): 571-610

Suddaby, Roy and Royston Greenwood (2005): Rhetorical Strategies of Legitimacy. Administrative Science Quarterly, 50 (1): $35-67$.

Tiratsoo, Nick (2002): The American Quality Gospel in Britain and Japan, 1950-1970, in: Kerstin Sahlin-Andersson and Lars Engwall (eds.): The Expansion of Management Knowledge: Carriers, Flows and Sources, Stanford University Press: Stanford, 175-194.

Tolbert, Pamela S. and Lynne G. Zucker (1996): The Institutionalization of Institutional Theory, in: Steward R. Clegg, Cynthia Hardy, and Walter R. Nord (eds.): Handbook of Organizational Studies, Sage: London, 175-190.

Townley, Barbara (1997): The Institutional Logic of Performance Appraisal, Organization Studies, 18 (3): 261-285.

Townley, Barbara (2002): Managing With Modernity, Organization, 9 (4): 549-573.
Tuckman, Alan (1995): Ideology, Quality and TQM, in: Adrian Wilkinson and Hugh Willmott (eds.): Making Quality Critical - New Perspectives on Organizational Change, Routledge, London, 54-81.

van Leeuwen, Theo (2005): Introducing Social Semiotics, Routledge: London et al.

Walgenbach, Peter (1998): Personalpolitik aus der Perspektive des Institutionalistischen Ansatzes, in: Albert Martin and Werner Nienhüser (eds.): Personalpolitik: Wissenschaftliche Erklärung der Personalpraxis, Rainer Hampp Verlag, München/Mering, 267-290.

Walgenbach, Peter (2000): Die normgerechte Organisation: Eine Studie über die Entstehung, Verbreitung und Nutzung der DIN EN ISO 90ooer Normenreihe, Schäffer-Poeschel: Stuttgart.

Walgenbach, Peter (2006): Neoinstitutionalistische Ansätze in der Organisationstheorie, in Alfred Kieser and Mark Ebers (eds.): Organisationstheorien, 6th ed., Kohlhammer: Stuttgart, 353-401.

Walgenbach, Peter and Nikolaus Beck (2002): The Institutionalization of the Quality Management Approach in Germany, in: Kerstin Sahlin-Andersson and Lars Engwall (eds.): The Expansion of Management Knowledge: Carriers, Flows, and Sources, Stanford University Press, Stanford, 145-174.

Wallerstedt, Eva (2002): From Accounting to Professional Services: The Emergence of a Swedish Auditing Field, in: Kerstin Sahlin-Andersson and Lars Engwall (eds.): The Expansion of Management Knowledge: Carriers, Flows and Sources, Stanford University Press, Stanford, 246-276.

Weick, Karl E. (1979): The Social Psychology of Organizing, Addison-Wesley: Reading, MA.

Wruck, Karen Hopper and Michael C. Jensen (1994): Science, Specific Knowledge and Total Quality Management, Journal of Accounting and Economics, 18 (3): 247-287.

Zbaracki, Mark J. (1998): The Rhetoric and Reality of Total Quality Management, Administrative Science Quarterly, 43 (3): 602-636.

Zilber, Tammar (2002): Institutionalization as an Interplay Between Actions, Meanings and Actors: The Case of a Rape Crisis Center in Israel, Academy of Management Journal, 45 (1): 234-254.

Zucker, Lynne G. (1977): The Role of Institutionalization in Cultural Persistence, American Sociological Review, 42 (5): 726-743

\section{Biographies}

Florentine Maier is Research Assistant in Nonprofit Management at Vienna University of Economics and Business Administration, Austria. Her research interest is the spread of managerial ideas and practices in organizations.

Julia Brandl is a Postdoctoral Associate with the Institute for Organization and Organizational Behavior at the Vienna University of Economics and Business Administration, Austria, and visiting professor at the University of Innsbruck and Arhus Business School. Her research focuses on legitimacy, power and the use of accounting instruments in organizations. 